\title{
Écrire après le cinéma, dir. J. BAETENS et N. COHEN
}

\section{Roberta Sapino}

\section{(2) OpenEdition \\ Journals}

\section{Edizione digitale}

URL: https://journals.openedition.org/studifrancesi/23412

DOI: $10.4000 /$ studifrancesi.23412

ISSN: 2427-5856

\section{Editore}

Rosenberg \& Sellier

\section{Edizione cartacea}

Data di pubblicazione: 1 avril 2020

Paginazione: 236-237

ISSN: 0039-2944

\section{Notizia bibliografica digitale}

Roberta Sapino, «Écrire après le cinéma, dir. J. baEtens et N. cohen», Studi Francesi [Online], 190 (LXIV | I) | 2020, online dal 01 mai 2020, consultato il 03 août 2021. URL: http://journals.openedition.org/ studifrancesi/23412 ; DOI: https://doi.org/10.4000/studifrancesi.23412

Questo documento è stato generato automaticamente il 3 août 2021.

\section{(c) (†)}

Studi Francesi è distribuita con Licenza Creative Commons Attribuzione - Non commerciale - Non opere derivate 4.0 Internazionale. 


\title{
Écrire après le cinéma, dir. J. BAETENS et N. COHEN
}

\author{
Roberta Sapino
}

\section{NOTIZIA}

Écrire après le cinéma, dir. J. BAETENS et N. COHEN, Montréal, Les Presses de l'Université de Montréal, 2019, “Études françaises" 55, 188 pp.

1 In un mondo che sempre di più tende alla inter- e transmedialità, le relazioni tra letteratura e cinema sono ben lontane dal limitarsi al semplice adattamento, al passaggio di contenuti e di forme da un mezzo espressivo all'altro. E se è vero che molte categorie che qualche decennio fa sembravano destinate a soccombere (a cominciare dalle notions périmées additate da Robbe-Grillet) godono ancora di buona salute, è vero anche che hanno subito scossoni, assestamenti, ibridazioni che la critica contemporanea non può esimersi dal considerare. Tra queste, la nozione di genere è senz'altro una delle più resistenti, nonché delle più problematiche, e rimane uno strumento tanto utile quanto discusso sia in letteratura che in ambito cinematografico. Proprio all'intersezione tra queste due modalità espressive si situa l'interrogativo comune ai contributi qui raccolti, che Jan BAETENS e Nadja COHEN hanno cura di dettagliare nella ricca introduzione: Que fait le cinéma aux genres littéraires? (pp. 5-12).

Il primo contributo, intitolato Genre romanesque et romanesque cinématographique: un désir de blockbusters et de cinéma de genre dans le roman contemporain français (pp. 13-27), riformula la nozione di romanzesco alla luce dell'imporsi dell'intermedialità come modalità di rapporto col mondo. Il romanzesco cinematografico, osserva Fabien GRIS in relazione a Magie industrielle di Patrice Blouin e L'Étoile du Hautacam di Pierric Bailly, non è più una fonte di materiali per pastiche e parodie, ma un oggetto di desiderio, una sorta di mito al quale tendere: "Romanesque" [...] se dirait donc ici d'une existence qui s'interprète, se pense, se vit par référence au cinéma» (p. 25). 
Morgane KIEFFER si concentra sui romanzi Western e Journée américaine, nei quali l'immaginario cinematografico d'oltreoceano è presente sia sul piano tematico e geoculturale, sia sul piano estetico, nell'integrazione di motivi, vocaboli e strutture narrative appartenenti al cinema popolare americano. È proprio sollecitando riferimenti cinematografici allo stesso tempo esotici e familiari e facendo leva sul potenziale figurativo delle immagini evocate che la scrittura di Montalbetti riesce a dar luogo a un dialogo con il lettore fondato sull'“invitation à l'émotion" (p. 41) (La botte du cowboy. Surexposition du cliché et sensibilité romanesque dans les romans cinéphiles de Christine Montalbetti, pp. 29-41).

4 In Images de la femme aimée dans le cycle de Marie de Jean-Philippe Toussaint: entre roman et cinéma (pp. 43-56), Frédéric CLAMENS-NANNI smentisce l'opinione (già respinta dall'autore, ma piuttosto diffusa tra i critici) secondo la quale la scrittura di Toussaint sarebbe "cinématographique". L'analisi dei romanzi che compongono il ciclo di Marie e la comparazione con uno spettacolo realizzato dall'autore presso la Comédie de Clermont-Ferrand portano a concludere che, se è vero che l'impulso a scrivere nasce dalla doppia fascinazione per il cinema e per la letteratura, per Toussaint «le roman est un genre pleinement assumé pour ce qu'il est» (p. 55).

5 I contributi di Jan BAETENS e Nadja COHEN portano in primo piano categorie di testi che rimangono ancora in gran parte da scoprire: il ciné-roman-photo, che BAETENS definisce un anello mancante nella storia del cinema raccontato, e i journaux de tournage, che a causa della loro eterogeneità risentono di una collocazione problematica sia in ambito editoriale, sia rispetto agli studi letterari. Il ciné-roman-photo, sostiene BAETENS a partire dall'analisi di due diverse trasposizioni di Ascenseur pour l'échafaud di Louis Malle (a sua volta trasposizione di un romanzo di Noël Calef), si costruisce nella tensione tra volontà artistica e imperativi tecnici, editoriali, commerciali, e testimonia l'importanza di «ne pas dissocier histoire du cinéma et histoire du livre» (p. 60) (“Ascenseur pour l'échafaud" en images fixes, Louis Malle en roman-photo, Jan BAETENS, pp. 57-73). Anche il journal de tournage, dimostra cOHEN soffermandosi su tre esempi celebri (Journal d'un film di Cocteau, il diario tenuto da Truffaut durante le riprese di Fahrenheit 451 e Pas à pas dans la brume électrique di Bertrand Tavernier), è ben più di un semplice documento: da un lato, il regista-scrittore vi trova un luogo di negoziazione, ridefinizione e talvolta di avvaloramento del suo ethos individuale e artistico; d'altro lato, il racconto dell'impresa collettiva di produzione del film è condotto secondo codici espressivi che si rifanno al modello dell'epopea (Du récit épique à la construction d'un "ethos" d'auteur: les journaux de tournage de Cocteau, Truffaut et Tavernier, pp. 75-93).

6 Nathalie GILLAIN dimostra che le strategie retoriche e enunciative messe in opera da Henri Michaux hanno un'origine cinematografica, essendo in gran parte ispirate ai gesti impulsivi, talvolta aggressivi, del Charlot impersonato da Charlie Chaplin. In Charlot l'autore vede «la preuve d'une possible révolte du corps» (p. 105), la possibilità di sovvertire le convenzioni sociali e, in campo letterario, di trasgredire i codici dei generi letterari (Charlot, une source d'inspiration pour Henri Michaux: de la figuration de mouvements à la subversion des genres littéraires, pp. 95-113).

7 Marie MARTIN, infine, si spinge fino a ipotizzare l'emergenza nella letteratura francese contemporanea di un nuovo genere, fondato sulla nozione di proiezione intesa sia come l'applicazione della tecnologia cinematografica, sia come processo psicologico inconscio. Lo studio semantico e sintattico di un corpus di romanzi la cui trama ruota intorno a un'opera cinematografica (per esempio Cinéma di Tanguy Viel e Ni toi ni moi di 
Camille Laurens) consente di individuare i tratti salienti di questo genere nuovo, in cui la proiezione si configura come la forma espressiva dell'assenza, del trauma, del vuoto (L'écriture et la projection: un nouveau genre dans la littérature française contemporaine?, pp. 115-133).

8 Chiude il volume la sezione Exercices de lecture, che raccoglie due articoli slegati dal percorso tematico. François HARVEY legge l'opera di Hubert Aquin, e in particolare gli scritti più tardivi, per mettere in luce l'“esthétique de la marge" (p. 139) che la caratterizza. La scrittura di Aquin, resa porosa da un uso libero e talvolta falsificatore della pratica citazionista, suscita una serie di interrogativi non solo estetici, ma anche etici, identitari, esistenziali legati alla progressiva sparizione della figura dell'autore dietro all'“écran de décombres" che è il testo letterario (p. 155): spetta allora al lettore il compito di dar vita alle parole (Hubert Aquin "fade out": excentration, falsification et disparition dans les derniers écrits aquiniens, pp. 137-157). Gilles LAPOINTE ripercorre invece il lavoro di analisi critica e di valorizzazione dell'opera di Louis Hémon che Nicole Deschamps ha svolto durante la sua carriera all'Université de Montréal. Inserendosi nel filone dei nascenti postcolonial studies, Deschamps adotta un approccio quanto più possibile affrancato dal colonialismo culturale soggiacente alle interpretazioni fino ad allora proposte per l'opera di Hémon, in particolare per quanto riguarda la figura di Maria Chapdelaine (Post-colonialisme et modernité chez Louis Hémon: Nicole Deschamps et le mythe de Maria Chapdelaine, pp. 159-174). 